\title{
CMS in Public Administration: A Comparative Analysis
}

\author{
Daniela Louraçoㅇ, Célio Gonçalo Marques²*
}

${ }^{1}$ Polytechnic Institute of Tomar, Tomar, Portugal

${ }^{2}$ Techn\&Art, Polytechnic Institute of Tomar, Tomar, Portugal

Centre for Public Policy and Administration, University of Lisbon, Lisbon, Portugal

*Corresponding Author: celiomarques@ipt.pt

Citation: Daniela Louraço, Célio Gonçalo Marques (2022). CMS in Public Administration: A Comparative Analysis. Journal of Information Systems Engineering and Management, 7(1), 11688. https://doi.org/10.55267/iadt.07.11688

ARTICLE INFO

Received: 27 Aug. 2021

Accepted: 21 Jan. 2022

\begin{abstract}
There is a wide variety of content management systems (CMS) available on the market, each with its characteristics, advantages and disadvantages, but the open source, such as Joomla, WordPress and Drupal are the ones who stand out, duo to characteristics such as: ease of use, possibility of customization, support, security, adaptability and amount of resources available (modules, components and plugins). These solutions are extremely relevant for public organizations, bringing citizens and businesses closer to their governments, by providing a more direct and intuitive access to government information and services (Fang, 2002). To achieve the benefits of its implementation, it is necessary an analysis of the solutions available on the market and which ones are best suited to certain management objectives. Through a comparison of data and information collected, it is highlighted the advantages and disadvantages of each of the three CMS mentioned, especially which one is most indicated for a specific context of application and project typology in public administration, using for these rankings of use and popularity on platforms such as W3Techs and BuiltWith, as well as a set of supporting documentation.
\end{abstract}

Keywords: Content Management Systems, Online Content Management, Joomla, WordPress, Drupal, Public Administration

\section{INTRODUCTION}

The impact of globalization, the introduction of innovative information and communication technologies and the exponential increase in information available, together with the assumption that information, content, and even services should be available promptly and intuitively (Moore, 2014), has subjected organizations to find new and better ways to create, manage, treat and disseminate information and content, in order to meet the needs of the organization, employees and the public (Molina \& Camarero, 2004).

For Public Administration organizations, the reality is no different from any other organization (Silva \& Ribeiro, 2009), existing an increasing effort "to transform how they capture, store and make information available to meet business, employees and community requirements" (Moore, 2014, p. 4). This is possible by establishing their online presence, through the publishing of information and the creation of online content, in the hope that they too can achieve greater efficiency, effectiveness and organizational performance (Melitski, 2001), which ensures that the information they have, and the content they produce, is easily available, making it easier for employees to offer fast services and for the community to access the information and content they seek (Hartman, 2011).

These management technological solutions have an extremely relevant aspect for public organizations, in the way "it brings citizens and businesses closer to their governments" (Fang, 2002, p. 1), through a new and renewed approach to public management, a way of "providing citizens and businesses with more convenient access to government information and services, to improve the quality of the services and to provide greater opportunities to participate in democratic institutions and processes" (Fang, 2002, p. 4). This allows the organizations to respond to the new technological needs of communities, but also to enhance new and improved mechanisms of services to the public, necessary to maximize the success and optimization of the activities of these public entities, reducing costs, time and resources, but also improving structuring, controlling and management of intellectual capital.

Currently, the CMS's represent one of the management technologies that best responds to this Public Administration needs (Boiko, 2005), by representing a system that incorporates a whole panoply of tools that extend from the Web page to the most varied applications of content management. Allowing to create, manage, modify and publish online content, without the need for specialized technical knowledge (Aledo-Hernández, Guillen-Pérez, Martinez-Caro, Sánchez-Iborra, \& Cano, 2017). 
However, a CMS can do much more than that, according to Boiko (2005, p.79) it can cover "whatever part of your content creation and organization system you want it to", through the most varied tools. The latter were listed by Rockley and Cooper (2003, p. 301) in his work "Managing Enterprise Content: A Unified Content Strategy":

"predefined content repository model; support for content relationships; built-in reports [...]; simplified creation of metadata; pre-configured system triggers [...]; version control; access control (security); integration with authoring tool(s); workflow".

All these tools can later be adapted to the needs of an organization in a combination "of clearly defined roles, formal processes, and a supporting systems architecture used by companies to produce, collaborate on, monitor, and publish" (Heckman \& Glantz, 2003, p. 667) of various types of information and content - documents, files, data, etc. - in a process that combines the collection of data, information and content with a defined and well-organized structure.

Therefore, despite the use and strength of CMS's currently being in the creation and management of Web content (WCMS), it goes far beyond this, presenting itself as a dynamic and versatile system, which can be expanded, through "new features and functions as and when your requirement changes unlike static and HTML site" (Patel, Rathod, \& Prajapati, 2011, p. 39), covering and combining in a single system other tools to manage the most varied types of content, namely: document management systems (DMS); component content management systems (CCMS); digital asset management systems (DAM); records management systems (RM); portals; e-mail management; workflow management; and the management of more specific processes within the organization.

Ultimately, it is the needs and objectives of the public organization, its employees and target audience that define which management components to use and which CMS best suits its reality and intended structure.

To this end, this paper initially will provide an overview of the content management systems on public organization, with a concrete contextualization of the typologies of content management systems available and an analysis of the three most used CMS on the market. With this contextualization, will be implemented an analysis and comparison of data and information, to identify which CMS solutions are most suitable for a specific organization and/or project typology, completed with a case study of these CMS in a public organization, the Comunidade Intermunicipal da Lezíria do Tejo (CIMLT), to understand their advantages and disadvantages, but most of all, their contributions to the public administrations and to an egovernance strategy.

\section{CONTEXTUALIZATION}

\section{Content management systems on public organizations}

With the challenge of obtaining a greater presence in the digital world and greater aggregation of processes and content by public organizations, the term e-government or electronic government emerges, which represents a strategy for the use of information technologies in Public Administration, at national, regional and local levels, by improving the quality of services that governments provide to citizens and businesses (Falcão,
Monteiro, \& Marques, 2014).

It represents a redefinition of the concept of information management, at the Public Administration level, in the way services are provided and information is disseminated (Svärd, 2017), based on the use of information and communication technologies, previously only available in person, which promote the effectiveness, efficiency, quantity and quality of the information made available, with a substantial cost reduction (Falcão, Monteiro, \& Marques, 2014), as well as new and improved mechanisms of interaction with citizens (Campos \& Marques, 2006).

However, the goal of e-government is not only to transform traditional information into online information, by making it accessible via the Internet and/or Intranets, or by making available public administrative processes in electronic platform (Campos \& Marques, 2006). It is also a way to reach a certain level of compliance and involvement by the entire public organization, which implies carrying out an introspection on the objectives and strategy of the company itself in its institutional context and surrounding environment, taking into account the external needs of search, consultation and use (Silva \& Ribeiro, 2009).

Therefore, current solutions that respond to new egovernment strategies, go through a more broad and proactive approach to all the information inherent to the organization, integrating structured content (financial data, company information and documents) and unstructured content ( the largest portion within an organization, which may be in the form of e-mails, audio files, videos or images), having a more holistic content management strategy (Moore, 2014; Balasubramanian, Venkataramanan, \& Durbha, 2017), where all the information and content generated, must be interconnected with the various elements of the organization (Palmisano \& Rosini, 2003).

To achieve this interconnection, there must be a focus on technologies that integrate the Internet and Intranets, contributing to a centralized, systematized and structured management of information, content, activities and processes (Molina \& Camarero, 2004). However, since we are discussing public organizations, these technologies must respect certain legislative and legal requirements inherent to the sharing of information and content, especially with regards to their access and security.

According to Boiko (2005), the technologies that currently best respond to this reality are those aimed at content management, which allow the assemble and management of structured and unstructured content, by centralizing all, or a large part of, the organization's intellectual property and its processes and services, in a single online networked system "that citizens can use to access, create, disseminate, and use digital information" (Svärd, 2017, p. 4).

Specifically in Public Administration, content management promotes a substantial increase in flexibility through remote and updated network access, as well as more selective control "of which metadata is to be used in order to steer information rightly, rules that regulate access, search possibilities, and the integration of different information systems"' (Svärd, 2017, p. 5). These conditions, make content management technologies the right solution to improve the efficiency and effectiveness of services provided by public entities, but also their responsibility and transparency towards communities, through a search and 
usability of information and content, either by employees or by citizens, in a dynamic, safe, updated and direct way (Boiko, 2005).

Considering the variety of content management systems that exist, any public organization can now obtain the benefits of a content management, but also select the options(s) that best suits their needs and objectives. That said, the best way to obtain a CMS that adapts to all, or most, of the needs of the organization, is to identify those needs right from the start and whether they can or should be integrated. Thus, a market survey must be carried out to understand which type of CMS best suits the organization and which responds best to these needs.

For example, many organizations identify early on that they need a system that integrates document management (DMS), digital asset management (DAM) and Web content management (WCMS) components, but perhaps these needs can also be met with just a component content management system (CCMS) and a WCMS (Rockley \& Cooper, 2003), the first as a mechanism for managing data, information and original content and, the second, for editing, reviewing and publishing online content.

Essentially, it is crucial to find a way to treat "web content as a channel only" (Rockley \& Cooper, 2003, p. 301), and use other components to manage more specific information, always bearing in mind that the selection of the appropriate CMS falls mostly on the "information needs and the needs of the people managing such information" (Pullman \& Baotung, 2017, p. 9) and that there are no systems that fully integrate an organization because, like Byrne (2005, p.13) said "content anywhere, anytime, any format remains highly utopian".

\section{Typologies of content management systems}

In the matter of choosing the CMS that best suits the organization and its objectives, there are probably several options available that suit the needs of an organization or a specific project, perhaps the great initial doubt, is whether one should choose a Commercial CMS (paid), an Open Source CMS (free) or a Custom CMS, three of the large groups of CMS in the market (Keßler \& Alpar, 2009).

When looking closer to them, each type of CMS has its advantages and disadvantages, the feature that distinguishes them primarily and conditions or favors them, is its code, which directly influences three features: cost, customization and support (Patel, Rathod, \& Patel, 2010).

In Commercial CMS, the code is developed and reserved for the company that creates it, being the final goal to sale, having a large monetary investment to obtain greater customization and support (Barker, 2016). In Open Source CMS, the costs is low, since the code is freely available to everyone and developed by a community of programmers, mostly volunteers and, because of that, the customization or support are limited to this community (Barker, 2016). In Custom CMS, the cost is variable, depending on the objectives of the organization, because there is the resort to outsourcing services and/or the use of company internal resources, to develop a customizable alternative, created through a preexisting free solution and adapted to the needs and objectives of the organization that hires the service (Keßler \& Alpar, 2009).

In this context, Commercial CMS are the most complex solutions with the highest internal investment in the short and long term, monetarily, in personalization and in maintenance, but have the following advantages (Shah, 2012): [1] greater level of flexibility of editing both the front-end and the backend of the CMS, because they are created from scratch with specific rules and desired structure; [2] technical assistance and initial training for those who will interact with the platform, with greater integration and understanding by all stakeholders regarding the functionality of the CMS; [3] a high level of security regarding the code, which is not visible or available abroad and; [4] a control "over the entire environment and most modules that are created for it, so it creates a more user friendly and secure end product" (Shah, 2012 , p. 8). The only disadvantages are in the costs associated with these solutions, namely with the purchase of the commercial license of the CMS, by itself quite high, and gets substantially higher with the costs associated with customization, integration and maintenance (Barker, 2016).

In the case of Open Source CMS, as the name implies, they have an open and free code source, with "well tested, feature rich, and a large volume of contributed code and modules" (Barker, 2016, p. 20). Therefore, its great advantages are the low cost, personalization and usability level, by allowing the use, editing and adapting of the code as desired, and there is no "cost for the software, and anyone can download and install them on a Web server without cost" (Shah, 2012, p. 7). But it is important to note that, even though the CMS is free, there will always be costs associated, namely those of the purchase of the domain/Web hosting and the installation of the software (Barker, 2016). However, being created, distributed and maintained by a community of programmers, who directly influence the quality, assistance and safety of the same, they have as disadvantages a certain level of uncertainty and insecurity in its use (Shah, 2012) and, as a result, there is usually no guarantee or assistance in the stability and safety of the CMS (Keßler \& Alpar, 2009).

The Custom CMS's are a more versatile solution, situated between a Commercial CMS and an Open Source CMS, by representing a solution adapted and customizable to the needs and objectives of a given organization, whether in the short or long term (Keßler \& Alpar, 2009). These have their genesis on the Open Source CMS so, thanks to the open source code, they have as advantage the customization and, thanks to the outsourcing, greater support and assistance. However, "there is not much research on the customization [...] so companies do not have any good guidelines to follow" (Keßler \& Alpar, 2009, p. 130). Therefore, its major disadvantages are the same as the ones from an Open Source CMS and a Commercial CMS, the uncertainty in their use and additional costs in customization, integration and maintenance, namely, "in a significant amount of resources to design, built, and maintain compared to an off-the-shelf solution" (Townsend, Riz, \& Schaffer, 2004, p. 281), which results in "project costs difficult to estimate, and project management becomes an art rather than a repeatable process" (Keßler \& Alpar, 2009, p. 130).

Looking at the three types of software and taking into account the current conjuncture of constant sharing and renewal of information and content, as well as the speed with which the software evolves, the creation of a CMS from scratch can represent a long-term problem, obsolescence, because it was designed taking into account a conjuncture and 
needs of the organization at a given time and, any update or upgrade, implies high costs to change the code (Barker, 2016). On the contrary, free CMS's and created based on these, have regular free updates, and some "mature and well-used enough to compete against any commercial offering" (Barker, 2016, p. 40), which with some maintenance, can be kept up to date in a more flexible and monetarily accessible way.

Given this reality, there are already many companies that prefer the use of more flexible, customizable, and versatile solutions:

"adaptable to dynamic changes of the modern business environment, they need more control over their software costs, security and trust [...] they need to be independently of individual software vendors" (Lazarica \& Dediu, 2013, p. 75).

Because of this, Open Source CMS's and Custom CMS's are currently the most usual choice by organizations, and there are perhaps "more open source options available in CMS's than in any other genre of software" (Barker, 2016, p. 36).

\section{Top free content management systems on the market}

Currently, there is a large spectrum of CMS's available on the market, but the recurring choice falls on three main CMS's: Joomla, WordPress and Drupal. These are part of the Open Source CMS's, with free open source code, available for any user, where all tools are developed and supported by a developer community (Bonfield \& Quinn, 2007).

Joomla

Joomla is one of the most intuitive and versatile CMS's on the market, currently used by international and national organizations such as Harvard University, IKEA, Lipton, Danone, Porsche, Peugeot, APAV, Portuguese Institute of Blood and Transplantation, Camões Institute, Caritas, National Library of Portugal and the Diplomatic Portal.

It was designed for both the most basic of users (Marriott \& Waring, 2011), as well as the more experienced ones, to create and design relatively fast a "highly interactive multilanguage websites, online communities, blogs, and ecommerce applications" (Harwani, 2009, p. 3).

By being characterized as a CMS, it is a software based on a Web server that controls all the content of the website through a database, being managed online through the administration tool (back-end), within which there are several modules, components and plugins "for adding features to your websites, such as main menus, polls, popular items, search, RSS feeds, and so on" (Harwani, 2009, p. 3), which are subsequently presented on the final Web platform (front-end), visually and structurally designed based on a template.

A CMS like Joomla has several features, but it is simple and intuitive structure, together with a short learning curve, are the main reasons that justify its success to this day, in addition to the large repository "of free extensions available, [and] frequent updates both to add new features and to improve security and stability, and a big support community" (Vliet, 2007, p. 19) which, as a whole, are advantages that can supplant the choice by other CMS on the market or by paid and created versions from scratch.
Drupal

Drupal, like Joomla, is one of the most widely used free CMS's on the market, being used by large international and national organizations such as Cambridge University, Tesla, NASA, Lifetime Television, Al Jazeera, ANA Airports of Portugal, Sporting Clube de Portugal and Sumol+Compal (Byron, Berry, \& Bondt, 2012) (Drupal, 2020) but, unlike the latter, Drupal presents a larger learning curve, because it "requires a significant effort to fully understand it, due to its complexity and difficulty of customization" (Baptista, 2014, p. 24) being, therefore, directed to more experienced users and looking for a higher level of customization.

The operational system of Drupal, is based on a Web server, a database and PHP programming language, the latter, allowing to add "several subsystems, such as user session handling and authentication, security filtering, and template" (Byron, Berry, \& Bondt, 2012, p. 8) rendering.

Despite the complexity of the system, it is easily edited and managed online through the administration tool, where it is possible to install and uninstall several modules, many of them free, which allow "expand the functionalities of the site, [...] such as form, language, security, and more modules" (Baptista, 2014, p. 25), subsequently presented on the website, which is based on a theme.

It has an extremely organized content management structure, with a level of complexity above other CMS, but with a flexible edition, with numerous free modules, that uplift its management capabilities and, not mentioning, its high level of customization, although this implies a level of knowledge in Web languages above average. However, in terms of back-end management, presents a "confusing management area, as well as its difficult-to-understand terminology" (Ferreira \& Glanzmann, 2011, p. 195), which makes tasks like adding a theme, long-time consuming.

As a whole, these characteristics explain the use of Drupal by large organizations, which have more specialized resources in the area and more specific and complex management objectives, aiming to obtain a unique platform, tailored to their needs/requirements (Baptista, 2014).

\section{WordPress}

WordPress, despite generating controversy as to its definition as a CMS, for not presenting in its programming structure a management and administration of content such as Joomla or Drupal (Shah, 2012, p. 10), deserves consideration for its evolution as a software, by moving from a blog manager to a more versatile platform (Patel, Rathod, \& Patel, 2010), but above all by the percentage of $63 \%$ of users it currently has (W3Techs, 2020), which includes organizations such as The New Yorker, BBC America, Sony Music, The Walt Disney Company, Mercedes-Benz, Harvard Gazette, National Health Service, INEM and TVI.

Like Joomla, WordPress is based on a server that controls all the content of the website through a database, and the management of its content is carried out online through the administration tool (back-end). In terms of functionality, plugins, represent the main elements of the system, by adding additional functionalities (Iqbal, Noman, Talpu, Manzoor, \& 
Abid, 2020) and allowing to control "every aspect of web site regarding the creation, organization and search engine optimization" (Patel, Rathod, \& Patel, 2010, p. 183).

Due to its short learning curve, structure and simple and intuitive interface, WordPress is one of the most used CMS, being the choice of "professionals, enthusiasts, hobbyists [and] people who have never had a website and don't know where to start" (Iqbal, Noman, Talpu, Manzoor, \& Abid, 2020, p. 1217). In addition, it is a CMS with a more aesthetic focus, having free templates of various genres and a large range of purposes, which are enhanced by the wide variety of free plugins available, all this "without needing to know any PHP or any form of HTML code" (Patel, Rathod, \& Patel, 2010, p. 27).

\section{METHODOLOGY}

This research aims to analyze the three most used CMS solutions available on the market today and which ones are best suited to certain organizational management objectives. Being the purpose to investigate a current phenomenon, thereby obtaining a set of data, information's and characteristics, we are facing a descriptive and explanatory study, completed with an analysis of one of these CMS in the context of a public organization, understanding in detail the way, the advantages and disadvantages of its use, which constitutes itself an exploratory case study with a high descriptive aspect.

As such, the method passes through the collection of qualitative and quantitative data, initially by collecting a set of data regarding the three most used CMS today and its evolutions over the years, using for this matter, rankings popularity and use on platforms such as W3Techs and BuiltWith, secondly a research and analysis of the state of the art regarding the CMS identified, namely their basic characteristics, advantages and disadvantages, using for this, a set of supporting documentation and, to complete an exploratory case study of the use of Joomla in a public organization.

Through an analysis and comparison of the data and information collected, its identified which CMS solutions are most suitable for a specific organization and/or project typology, considering characteristics such as knowledge and experience of its employees, monetary and human resources availability, learning curve, management structure, security and stability of use.

Through the case study, it will be implemented an observation and identification of the CMS's in use in a public organization, namely the municipalities belonging to CIMLT, by assessing the HTML code of each, allowing to understand the potentialities of the CMS they use, is advantages and disadvantages, but most of all, their contributions in public administrations and to an e-governance strategy. Additionally, to complement the information gathered by the observation, a document analysis will also take place, in particular of public official documents, where the major focus will be on the contract specifications and user manuals on the implementation and maintenance of the CMS's in use by the organization, but also an interview, carried out with the head of CIMLT's information systems manager, with a set of structured questions, to clarify the process of implementation of the CMS's and the strategy and fundamental objectives in which they were structured.

\section{DISCUSSION OF RESULTS}

\section{Implementing and selecting a CMS}

The implementation of a CMS represents a time-consuming and complex work in its structuring, not at all limited only to the technology and tools that CMS offers, including a whole retrospective on what types of content will be published and how information and content "must be structure within the framework of comprehensive Information Model and under the control of a contented management system" (Hackos, 2001, p. 8), which must organize, categorize, and structure all resources, so they can be stored, used, published, and reused in various forms and by various users.

Since the structuring model is the basis of how the CMS should be implemented, it also represents a motto for choosing the CMS that best suits this structure, and which will allow "develop processes to author and categorize content, house it in a repositor, repurpose it, and deliver it effectively in multiple media, using personalization and customization techniques" (Hackos, 2001, p. 9). But not only, the choice must also fall in which one is most adapted to users needs, both outside and within the organization, as well as to its objectives and strategy, financial capacity and time and people available to implement and maintain it. According to Cruz (2007, p. 86), there is a set of desirable characteristics in the choice of a CMS, within the ones mentioned, the most relevant are:

1. Ease of use

2. Low acquisition cost

3. Low maintenance cost

4. Speed in content development

5. Speed and accuracy in publishing content

6. Functions for collaborative work

7. Single access point

8. Customizable access via user type

9. Security

There are numerous options of CMS's on the market, which correspond less or more to these characteristics, from free to paid, with only one type of management and with various types of content management, interconnected or not, more or less intuitive, more or less customizable. Each has certain characteristics, which predispose them to be selected for specific activities or tasks, and there is effectively no fixed criterion of which is best for a given area or function, as each "is worked on specific criteria and you have to select which is fit as per your need." (Patel, Rathod, \& Prajapati, 2011, p. 39).

The certainty is that by selecting a CMS that has the desirable characteristics already mentioned, any company or individual can save time, resources and funds, not only in the development and maintenance of the tool itself, but above all because it will be possible to centralize all information by allowing "to collect data, information and knowledge from various sources such as: corporate applications, departmental and corporate databases, content in any extension [...], on any type of media and that will be published in any repository, intra, or extra organization" 
(Cruz, 2007, p. 86).

Analysis and comparation of data from the three most used CMS solutions on the market

Within the most used Open Source CMS's today, we can highlight, in order of use, WordPress (63.5\%), Joomla (3.9\%) and Drupal (2.6\%) (Figure 1) (W3Techs, 2020).

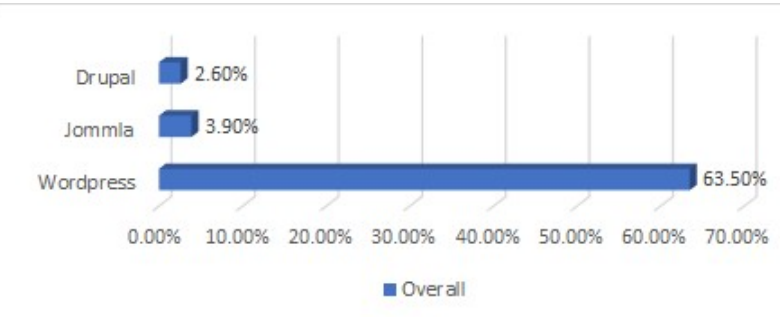

Figure 1. Use of Content Management Systems (W3Techs, 2020)

The scenario would be quite different before 2014, when Joomla's popularity began to decline and eventually lost the lead to Drupal's favor and has since declined dramatically, with WordPress overtaking both its competitors in the Open Source CMS market (Figure 2).

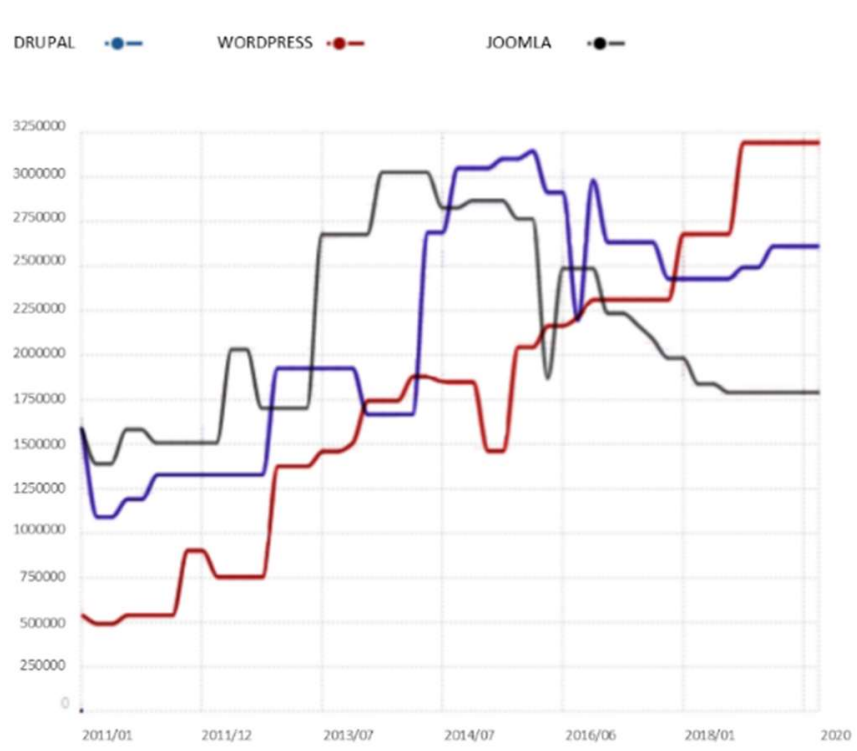

Figure 2. Use of CMS's worldwide since 2011 (BuiltWith, 2020)

The great advantages that are obtained with the use of these CMS, fall mainly in aspects such as: customization, whether in terms of the themes available to change the visual design of the platforms or the availability of resources for managing content on the front-end and back-end; support, often through online communities or even from the developers themselves; usability, users greatly value the ease with which they learn to use the various resources available; and the safety of the tool itself.

Table 1. Comparison between CMS WordPress, Joomla and Drupal (Benitez, 2017) (Patel, Rathod, \& Parikh, 2011)

\begin{tabular}{|c|c|c|c|}
\hline & WordPress & Joomla & Drupal \\
\hline Cost & Free & Free & Free \\
\hline Use & +24.808 & +1.844 & +1.829 \\
\hline Themes (Free) & $+4,000$ & $+5,000$ & $+2,000$ \\
\hline Plugins (Free) & $+54,000$ & $+3,000$ & $+25,000$ \\
\hline Pros & $\begin{array}{ll}\text { - } & \text { Low customization; } \\
\text { - } & \text { Easy usability; } \\
\text { - } & \text { Excellent support. }\end{array}$ & $\begin{array}{ll}\text { - } & \text { Average customization; } \\
\text { - } & \text { Easy usability; } \\
\text { - } & \text { Excellent support. }\end{array}$ & $\begin{array}{ll}\text { - } & \text { More advanced; } \\
\text { - } & \text { High customization; } \\
\text { - } & \text { Better performance and security; } \\
\text { - } & \text { Good support. }\end{array}$ \\
\hline Cons & $\begin{array}{l}\text { - Customization, in, addition to } \\
\text { the available themes, is only } \\
\text { possible with basic knowledge in } \\
\text { HTML. } \\
\text { - Updates can cause some conflicts } \\
\text { with plugins already installed. }\end{array}$ & $\begin{array}{l}\text { - The modules and components } \\
\text { are more complex than } \\
\text { WordPress plugins but, on the } \\
\text { other hand, allows for greater } \\
\text { customization. }\end{array}$ & $\begin{array}{l}\text { - Users need knowledge in HTML, } \\
\text { PHP and other Web languages to } \\
\text { get all the benefits of this } \\
\text { software. }\end{array}$ \\
\hline
\end{tabular}

Within the three Open Source CMS's mentioned, off course some of these aspects may be, more or less, valued by users. Looking at the following table (Table 1), it is possible to understand that there are significant differences, which justify the current level of use of each.

In the case of WordPress, although very focused on the area of blogs, offers a wide range of themes/templates to change the design of the front-end, feature highly valued today, being also an intuitive tool and easy to understand, even for little to nothing experienced users, which includes "features such as drag and drop, resulting in the generation of code without technical intervention" (Shah, 2012, p. 10). Given this features, some experts in the field admit that WordPress may not exactly be a CMS and should be excluded, since in the literal sense of the concept, "it would be more correct to describe such products as "website builders' than Web Content Management Systems" (Shah, 2012, p. 10), because a CMS presents programming in its structure that allows the administration and maintenance of the content produced (Bárcia, 2011), something that WordPress does not possess.

In the case of Joomla, it is more adapted to users with a median experience in the area, having a more intuitive usability strand, where its "administration usability and learning curve is better" (Shah, 2012, p. 10) than other CMS's on the market, as is the case with Drupal, but more complex than WordPress. In 
addition, it offers "many advanced features in addition to the normal content management features" (Shah, 2012, p. 10), like components, modules or plugins that facilitate the management and organization of content, either on the frontend or back-end of the website. However, it has as disadvantages, in terms of design limitations, by having a limited set of free templates, especially compared to WordPress.

Finally, Drupal presents itself with a higher level of complexity compared to Joomla and WordPress, especially in the administrative part of the platform, being more directed to experienced users with knowledge in HTML, PHP and other eb languages. Although the complexity is disadvantageous for less experienced users, it offers greater customization, performance and security, being one of the most used options by organizations that want to opt for an Open Source CMS, with characteristics of a Commercial CMS, using it to create, for example, intranets and platforms internal to the company.

Given the foregoing, it is noticeable that the choice of a CMS depends on the objectives, structure and strategy of each public organization. However, it should be noted that some are more appropriate to smaller projects, such as WordPress, and others adapted to larger projects, such as Joomla and Drupal and, as a whole, all allow, with less or greater implication of resources and time, to create and develop an efficient and up-to-date online content management platform.

\section{Case Study}

In view of the analysis of the three most used CMS's on the market, it is important to research and analyze them in the specific context of content management, applied to an organization, in this case a public organization, the Comunidade Intermunicial da Lazíria do Tejo (CIMLT), based on a study of their use, structure, resources, archive of documents, application forms, download documents, management of news and notices, contacts, etc.

This case study will provide essential data by identifying, through the techniques of observation, document analysis and an interview, a characterization of the platforms under study, to trace a more detailed study of each of these tools, in particular in terms of their genesis, structure, characteristics and identification of the CMS's in use in the municipalities belonging to CIMLT, aspects relevant so that any organization, public or private, can ascertain the potential of the implementation of these CMS's in the management of their online content.

\section{The genesis of CIMLT CMS platforms}

Prior to the current portals used, according to the interview conducted with Carlos Diogo, information technology manager of CIMLT (Louraço, 2020), the municipalities used the Microsoft Sharepoint platform, which had two major disadvantages: high licensing costs and lack of absolute control over the pages.

To address these disadvantages, the creation and reformulation of the institutional portals of the municipalities belonging to CIMLT begins to be projected in 2002, a reformulation that according to Carlos Diogo focused on the change of platform, keeping the server centralized in CIMLT.

For accomplishing that goal, it was created the Ribatejo Digital project, launched by the Association of Municipalities of Lezíria do Tejo, now CIMLT, having as partners the 11 municipalities of Lezíria do Tejo (Almeirim, Alpiarça, Azambuja, Benavente, Cartaxo, Chamusca, Coruche, Golegã, Rio Maior, Salvaterra de Magos and Santarém), as well as the Região de Turismo do Ribatejo, NERSANT, the Instituto Politécnico de Santarém and the newspapers "O Mirante" and "O Ribatejo" (Ribatejo Digital, 2002).

The purpose of this project was to create "a Digital Region, constituting the catalyst for innovation and competitiveness in the region" (CULT, 2007, p. 102). Therefore, the primary objective was to enhance physical access to the Internet by the population of the 11 municipalities in the region, through the provision of computers, allowing the use of the content and services available online, as well as the creation of a set of digital platforms that would allow electronic contact between the local and central public administration and its citizens (CULT, 2007). For this to be possible, websites were created "for municipalities that did not yet have one, while the existing ones were reformulated [in a] strategic orientation of incorporating the logic of the public service" (CULT, 2007, p. 102), which provided varied information, features and new online services, extremely valuable for both the citizen and the municipal services themselves (Lopes, 2005).

The creation and restructuring of the websites of CIMLT municipalities

The objective of the creation and restructuring of the websites of CIMLT municipalities was achieved in 2012, with a complete restructuring of the websites (CIMLT, 2011) of ten of the eleven associated municipalities, by implementing a set of information and online services, namely: payment of water bills or licenses; applications for licensing; consultation of process information; online requirements; reading of counters and communication of breakdowns; among other online services (CULT, 2007) (Talixa, 2002).

In addition to these objectives, by consulting the contract specifications of September 2011 (CIMLT, 2011), regarding the restructuring of the websites of each of the municipalities, we understand that CIMLT's primary objective was to obtain platforms that are uniform to each other, in terms of visual appearance and management principles, with a modern design that included management applications that facilitated intercommunication and services between municipalities and citizens, but that also provided better access to content and services by communities.

This restructuring entailed the adoption of dynamic and flexible content management platforms, keeping the platforms (server) centralized in CIMLT (Louraço, 2020), thus allowing the management of all this information and a more direct and dynamic creation of content but, according to Carlos Diogo, also weighed other factors for the choice of a CMS, namely (CIMLT, 2019): [1] to be open source and, as such, without licensing costs; 
[2] to be used on other thematic websites in other municipalities and; [3] individual and autonomous control of the instances of the websites by the specific members of the community.

\section{Identification and characterization of platforms}

After viewing and analyzing each of the eleven platforms, it was possible to identify that all the municipalities, with the exception of the municipality of Cartaxo, have a very similar front end to each other, in terms of functionalities and visual aspect, which immediately aroused the doubt whether we were facing different CMS's or just one specific CMS.

The doubt was scattered immediately by consulting the contract specifications and analyzing the source code of each platform, where it was possible to assess that it is only a specific content manager, common to ten of the municipalities of CIMLT, the CMS Joomla, applied in the same version and with the same external and internal characteristics. Being the exception the municipality of Cartaxo, that keeps his page without the use of CMS.

The choice of CMS Joomla the software for the global content management of CIMLT platforms was justified because it represents one of the main content management systems of today and quite popular and stable when implementing the project, between 2011 and 2012 (Louraço, 2020), which allowed and continues to allow, a process of creating websites with faster and less monetary investment. In addition, in the long term, its maintenance and management is made easier by having a smaller learning curve, allowing each of the platforms to be autonomously managed by each municipality (CIMLT, 2015).

Therefore, according to Carlos Diogo (Louraço, 2020), the implementation of CMS Joomla is justified because it fulfills the essential requirements for the project, especially with regard to stability and free licensing, but also for allowing easily and intuitively to manage various institutional contents online, like documents for consultation and download, calendar of events and galleries of images, on a regular and daily basis by the professionals of the municipalities.

In addition to the aspects mentioned above, another essential point for selection Joomla, is regarding its versatility and personalization capacity when it comes to content management options and the visual and structural aspect, allowing it to be updated to the needs of the organization and the functional visual evolution of the platforms itself. Specifically, in this project, according to Carlos Diogo (Louraço, 2020), the platforms usually have the same predefined template, which explains their similar appearance, but they have a few distinct aspects, like the use of different modules and dispositions of elements on the overall frontpage, not forgetting to mention the use of distinct logos and coats of arms by municipality.

However, it is mentioned that in 2015 a new restructuring of the websites was carried out, focused on the organization and management of information and content, adopting a more intuitive system, using for this a new template, with a more appealing design, thereby continuing to allow access to all content related to the most varied sectors of municipal activity, be it social action services, culture, tourism, education, sports, municipal works, associative, fees and licenses, PDM, forms and other documents, always in order to bring the citizens closer to their municipalities (CIMLT, 2015).

More recently, in November 2019, with the increase of the access to the platforms by diverse electronic devices, the websites had a new restructuring, keeping all existing content and the Joomla CMS, but adopting a template with a more appealing and current design, adapted to mobile devices, android and iOS platforms (CIMLT, 2019).

According to Carlos Diogo (Louraço, 2020), the structure and choice of the current CMS was and remains adequate, allowing not only financial advantages and the achievement of the desired management and control objectives, but also the possibility of evolving alongside the recurrent technological advances, without the need for the adoption of other technologies available on the market.

\section{CONCLUSION}

With the digital revolution, not only the formats and the amount of information disseminated have changed and increased, but also our culture and the way Public Administration manages it in the face of this reality (Badke, 2010), by displaying a growing need to manage and control this volume of information and to convert documents and various information in online content. This forced an adaptation and investment in technologies such as CMS's, which allow to publish, edit, modify, organize, delete and maintain, based on a single interface, all content and information online, with little to low effort (Srivastav \& Nath, 2016).

Although there is a wide variety of CMS's available on the market, each with its characteristics, advantages and disadvantages, the Open Source ones stand out, namely the most popular, such as Joomla, WordPress and Drupal. They do so, not only because they are free, but also because they represent the most powerful content management tools of today, by offering an up-to-date online system with a wide range of dedicated developers, and by allowing to control a huge amount of content and activities in these platforms in an intuitive way, like who has access to information and who creates, alters, and stores content on the platform. In addition, they are one of the few tools that have accompanied the expansion and evolution of the Internet, as well as the constant increase of information in recent years, allowing its users to maintain their current platforms in a constantly changing online universe in relative safe way (Boiko, 2005).

Therefore, the content management systems mentioned represent viable solutions, directed to the achievement of various content management objectives and adaptable to various types of projects, each having specific characteristics, which adapt more or less to certain projects, depending on their characteristics, being important a thought and fully concrete consideration to choose the one that best suits the needs of a particular organization or project.

In a context of a public organization, these contribute to 
improve the efficiency and effectiveness of services provided by public entities, but also their responsibility and transparency to communities, through a dynamic, secure, upto-date search and usability of information and content (Boiko, 2005). Throughout the case study carried out at CIMLT, it was possible to conclude all the qualities mention, but the choice of a CMS has the content management on the municipalities that make part of CIMLT, fell on points such as exemption from license costs, its versatility and adaptability and the more direct, secure and concrete control of the activities and users who interact with the platform.

Unfortunately, the case study did not cover all the CMS studied, having fallen only in one CMS common to the municipalities under study, the CMS Joomla, and the choice was justified by this being one of the main content management systems used and quite popular and stable when the project was implemented back in 2012, allowing a process of creating websites with faster and less monetary investment, as well as a more safe and controlled maintenance of information and various institutional contents in an autonomously way by each of the municipalities (CIMLT, 2015).

Therefore, although only the CMS Joomla has been explored in a practical context, looking at the common characteristics it has with the remaining CMS under study, it is possible to conclude that by adopting this technologies, public organizations, achieve a greater level of openness, integration and dynamism, which allows to correctly put into practice a egovernance strategy, adaptable to current technological changes, constantly evolving and changing, but transcendent enough to allow it to meet the management needs of the organization itself and its communities and companies, which is why the choice of the best suited CMS to the public organization is decisive to achieve the ultimate goal of simplifying and enhancing the access to public information, content and services, benefiting citizens, business partners and the community as a whole.

\section{REFERENCES}

Aledo-Hernández, A.-J., Guillen-Pérez, A., Martinez-Caro, J.-M., Sánchez-Iborra, R., \& Cano, M.-D. (2017). Sistemas de gestión de contenido web: Uso y estudio comparativo inicial de su seguridad. XIII Jornadas de Ingenieria Telematica - JITEL2017, (pp. 86-92). Valencia.

Badke, W. (2010). Content, content everywhere. Onlinemag, pp. 52-55.

Balasubramanian, S., Venkataramanan, K., \& Durbha, K. (2017). Running at the Speed of Digital: Hyper-Digital Information Management. Cognizant.

Baptista, M. R. (2014). Estudo Comparativo de CMSs. Master Thesis, Universidade da Madeira, Centro de Competência de Ciências Exactas e da Engenharia.

Bárcia, L. (2011). A utilização da plataforma Joomla! na escola. Master Thesis, Universidade Católica Portuguesa, Ciências da Educação.

Barker, D. (2016). Web Content Management. Sebastopol: O'Reilly Media, Inc.
Benitez, C. J. (2017, November 20). Comparar Top 3 CMS (2017): WordPress vs. Joomla vs. Drupal. Retrieved June 20, 2020, from Web Hosting Secret Revealed: https://www.webhostingsecretrevealed.net/pt/blog/webtools/compare-top-3-cms-2017-wordpress-vs-joomla-vsdrupal/

Boiko, B. (2005). Content Management Bible. John Wiley \& Sons.

Bonfield, B., \& Quinn, L. S. (2007). Comparing Open Source CMSes: Joomla, Drupal and Plone. Retrieved March 26, 2019, from Idealware: shorturl.at/nMOP0

BuiltWith. (2020, July 24). BuiltWith. Retrieved July 24, 2020, from Joomla! Usage Statistics: https://trends.builtwith.com/cms/Joomla!

Byron, A., Berry, A., \& Bondt, B. D. (2012). Using Drupal (2 ed.). Sebastopol, EUA: O'Reilly.

Campos, R., \& Marques, C. (2006). O Governo Electrónico e os Sistemas de Informação Públicos em Portugal. Actas da 1. a Conferência de sistemas e Tecnologias de Informação (CISTI 2006), (pp. 421-437).

CIMLT. (2011, December 28). CIMLT. Retrieved August 27, 2020, from Lezíria do Tejo tem nova imagem na Internet: shorturl.at/drE59

CIMLT. (2011, October 7). Prestação de Serviços para Reestruturação dos Sites da CIMLT, Municípios Associados e do Portal do Ribatejo Digital. Retrieved August 25, 2020, from Base: contratos públicos online: shorturl.at/uPTW4

CIMLT. (2015, January 16). CIMLT melhora sites dos Municípios associados. Retrieved August 27, 2020, from CIMLT: shorturl.at/aciuK

CIMLT. (2019, January). Atualização de páginas de Internet. Retrieved August 27, 2020, from Base: contratos públicos online: shorturl.at/dCTU8

CIMLT. (2019). CIMLT. Retrieved August 25, 2020, from CIMLT melhora sites dos Municípios associados: shorturl.at/oHS35

Cruz, T. (2007). Fundamentos da gestão de conhecimento. Rio de Janeiro: Editora E-papers.

CULT. (2007). Projecto Ribatejo Digital. In CULT, 20 anos de associativismo municipal na Lezíria do Tejo (pp. 100-105). Forad'oras Lda.

Drupal. (2020, July 20). Casos de Uso. Retrieved July 20, 2020, from Drupal: https://drupal.pt/

Falcão, R. L., Monteiro, M. H., \& Marques, C. G. (2014). O nível de qualidade oferecido pelos serviços eletrónicos na Administração Pública Local em Portugal. Um caso de estudo na NUTS II - Lisboa. 14 ${ }^{a}$ Conferência da Associação Portuguesa de Sistemas de Informação (CAPSI 2014), (pp. 225-248).

Fang, Z. (2002). E-Government in Digital Era: Concept, Practice and Development. International Journal of the Computer, the Internet and Management, 10(2), 1-22.

Ferreira, F. G., \& Glanzmann, J. H. (2011). Sistemas de Gestão de Conteúdo: Comparativo - Drupal x Joomla! CES Revista, 25, pp. 191-206.

Hackos, J. T. (2001). Content Management for Dynamic Web Delivery. New York: John Wiley \& Sons, Inc. 
Hartman, E. (2011, July 21). Master Your Content Using the Content Management Lifecycle. Retrieved September 21, 2019, from CMS Wire: shorturl.at/imnC5

Harwani, B. M. (2009). Chapter 1: Introduction to Joomla! In B. M. Harwani, Foundation Joomla! (pp. 1-10). New York: Friendsof.

Heckman, J. M., \& Glantz, E. J. (2003, July). Review of "web content management: A collaborative approach" by Nakano, Russell Addison Wesley, Boston, 2002. Information Processing and Management: an International Journal, 39(4), 667-668.

Iqbal, M., Noman, M., Talpu, S. R., Manzoor, A., \& Abid, M. M. (2020, May). An empirical study of popular content management system - Wordpress vs Drupal vs Joomla. ICTACT Journal on Management Studies, 6(2), pp. 12141219.

Keßler, S., \& Alpar, P. (2009). Customization of Open Source Software in Companies. IFIP Advances in Information and Communication Technology, 299, pp. 129-142.

Lazarica, M., \& Dediu, F. (2013). Content Management Systems (CMS) Open Source Websites. Management Strategies Journal, 19, pp. 75-82.

Lopes, M. (2005, August 11). Portal Ribatejo Digital apresentado em Santarém. Retrieved August 28, 2020, from Tinta Fresca: shorturl.at/bnMO1

Louraço, D. (2020). A aceitação dos Sistemas de Gestão de Conteúdos nos Municípios: Um estudo na Comunidade Intermunicipal da Lezíria do Tejo. Master Thesis, Instituto Politécnico de Tomar - Escola Superior de Gestão, Tomar.

Marriott, J., \& Waring, E. (2011). The Official Joomla! ${ }^{\mathrm{TM}}$ Book. Boston: Pearson Education, Inc.

Melitski, J. (2001, December 10). The World of Egovernment and E-governance. Retrieved December 27, 2019, from http://www.aspanet.org/solutions/TheWorld of Egovernment and Egovernance.htm.

Molina, M. P., \& Camarero, C. G. (2004). La ciberadministración española en la sociedad de la información: retos y perspectivas. Ediciones Trea.

Moore, G. (2014). Transforming Local Councils in Australia: Information Management in the Digital Age. Australia: TechnologyOne. Retrieved September 21, 2019, from shorturl.at/cqvTU

Palmisano, A., \& Rosini, A. M. (2003). Capítulo 1 Abordagens Sistêmicas. In A. Palmisano, \& A. M. Rosini, Administração de Sistemas de Informação e a Gestão do Conhecimento (pp. 1-56). São Paulo: Pioneira Thomson Learning.

Patel, S. K., Rathod, D. V., \& Prajapati, J. B. (2011, May). Performance Analysis of Content Management SystemsJoomla, Drupal and WordPress. International Journal of Computer Applications (0975 - 8887), XXI(4), pp. 39-43.

Patel, S. K., Rathod, V. R., \& Patel, N. A. (2010). Open Source CMS Selection - A Mystery. International Journal on Computer Science and Engineering (IJCSE), pp. 24-28.

Patel, S. K., Rathod, V., \& Parikh, S. (2011). Joomla. Drupal and WordPress - A Statistical Comparison of Open Source CMS. 3rd International Conference on Trendz in
Information Sciences \& Computing (TISC2011), (pp. 182187). Chennai, India.

Pullman, G., \& Baotung, G. (2017). Content Management: Bridging the Gap Between Theory and Practice. New York: Routledge.

Ribatejo Digital. (2002). Ribatejo Digital. Retrieved August 28, 2020, from https:/www.cimlt.eu/todos-osdocumentos/118-revista-ribatejo-digital/file

Rockley, A., \& Cooper, C. (2003). Managing Enterprise Content: A Unified Content Strategy ( $2^{\underline{a}}$ ed.). Berkeley: New Riders.

Shah, R. V. (2012). Building a web content management system. Master Thesis, Faculty of San Diego State University.

Silva, A. M., \& Ribeiro, F. (2009, November). A gestão da informação na administração pública. Administração Pública Interface, pp. 32-39.

Srivastav, M. K., \& Nath, A. (2016, March). Web content management system. International Journal of Innovative Research in Advanced Engineering (IJIRAE), III, pp. 51-56.

Svärd, P. (2017). e-Government developmentnd its impact on information management. In Enterprise Content Management, Records Management and Information Culture Amidst E-Government Development (pp. 1-10). Cambridge: Chandos Publishing.

Talixa, J. (2002, November 18). Ribatejo Digital vai servir de experiência-piloto para o resto do país. Retrieved August 28, 2020, from Público: https://www.publico.pt/2002/11/18/jornal/ribatejo-digitalvai-servir-de-experienciapiloto-para-o-resto-do-pais176648

Townsend, J. J., Riz, D., \& Schaffer, D. (2004). Content Management. In Building Portals, Intranets, and Corporate Web Sites Using Microsoft Servers (pp. 279311). Boston: Addison-Wesley Professional.

Vliet, T. V. (2007). Proprietary Dynamic Web Design vs a CMS. Bachelor, Katholieke Hogeschool Kempen, Electronica-ICT.

W3Techs. (2020, July 24). Usage of content management systems broken down by ranking. Retrieved July 24, 2020, from W3Techs: shorturl.at/aeM47 